\title{
The Effect of (-)-Linalool on the Metabolic Activity of Liver CYP Enzymes in Rats
}

\author{
K. NOSKOVÁ ${ }^{1}$, G. DOVRTĚLOVÁ ${ }^{1}$, O. ZENDULKA ${ }^{1}$, R. ŘEMÍNEK ${ }^{2}, J_{\text {J JUŘICA }}^{1,2}$ \\ ${ }^{1}$ Department of Pharmacology, Faculty of Medicine, Masaryk University, Brno, Czech Republic, \\ ${ }^{2}$ Department of Biochemistry, Faculty of Science, Masaryk University, Brno, Czech Republic
}

Received August 26, 2016

Accepted October 6, 2016

\section{Summary}

$(-)$-Linalool is the major floral scent occurring mainly in families Lamiaceae, Lauraceae and Rutaceae and is the main active compound of lavender oil. The purpose of this study was to reveal the influence of subchronic systemic treatment with (-)-linalool on the metabolic activity of CYP2A, 2B, 2C6, 2C11 and $3 A$ in rat liver microsomes (RLM). The second aim was to reveal possible inhibitory effect of (-)-linalool on CYP2C6 in vitro. Wistar albino male rats were treated with (-)-linalool intragastrically at the doses of 40,120 , and $360 \mathrm{mg} / \mathrm{kg} /$ day for 13 days. Treatment with (-)-linalool at the dose of $360 \mathrm{mg} / \mathrm{kg}$ increased the metabolic activity of CYP2A assessed with testosterone as a probe substrate. (-)-Linalool showed weak competitive inhibition of CYP2C6 in rat liver microsomes, with $\mathrm{IC}_{50}$ of $84 \mu \mathrm{M}$ with use of diclofenac as a probe substrate.

\section{Key words}

$(-)$-Linalool • Rat liver microsomes • CYP450 • Metabolic activity

\section{Corresponding author}

J. Juřica, Department of Pharmacology, Faculty of Medicine, Masaryk University, 62500 Brno, Czech Republic. E-mail: jurica@med.muni.cz

\section{Introduction}

Linalool is a monoterpenic alcohol present either in monocotyledonous and dicotyledonous plants. There were identified two enantiomers in plants. (3S)-(+)-Linalool, also known as coriandrol, is the main component of essential oils of Coriandrum sativum seeds. (3R)-(-)-Linalool, known as licareol, is the main component of essential oil of Lavandula officinalis flowers. Except of the distribution, the enantiomers differ in a fragrance and biological activity. (+)-Linalool is described as sweet, floral and herbaceous while (-)-linalool as a woody, lavender-like aroma (Aprotosoaie et al. 2014). The subject of this study is (-)-linalool, the main active substance of Lavandula spp. which is used in traditional medicine to treat anxiety or mild depression (EMA/HPMC 2012). Many biological activities of (-)-linalool have been proven, for example anti-inflammatory (Peana et al. 2002), antimicrobial (Park et al. 2012) and antioxidant activity (Liu et al. 2012). Many studies have also shown diversity of other pharmacological properties such as sedative (Sugawara et al. 1998), anxiolytic (Souto-Maior et al. 2011), anticonvulsant (Elisabetsky et al. 1999), analgesic (Li et al. 2016) and local anesthetic activity (Zalachoras et al. 2010). Food supplements containing (-)-linalool whose efficacy in treatment of anxiety disorders was confirmed by clinical trial (Kasper et al. 2010) are available in Central Europe. Furthermore, lavender oil preparation has been licensed in Germany as a herbal medicinal product for the treatment of restlessness in anxiety disorders (Uehleke et al. 2012).

According to the increasing popularity of alternative medicine and rising use of herbal preparation, knowledge on pharmacodynamic and pharmacokinetic herbal-drug interactions are needed and required by state authorities in the registration procedure of herbal medication. The aim of this study was to evaluate the influence of subchronic administration of (-)-linalool on the metabolic activity of liver CYP2A, CYP2B, CYP2C6, CYP2C11 and 
CYP3A enzymes in rats and to determine their $\mathrm{IC}_{50}$ for a purpose to predict possible herbal-drug interactions.

\section{Methods}

Animals

Male Wistar albino rats $(280 \pm 20 \mathrm{~g}, 8$ weeks old $)$ were housed in groups of 5 under standard laboratory conditions $(12 / 12 \mathrm{~h}$ light-dark regime at the temperature $22 \pm 2{ }^{\circ} \mathrm{C}$ and room humidity $55 \pm 5 \%$ ). Water and pelleted diet were provided ad libitum. All experiments were performed in accordance with the Czech act No. 246/1992 and with the approval of both the local and national Czech Central Commission for Animal Welfare.

\section{Experimental design}

After 5 days of acclimatization, rats were randomly divided into four groups per 10 animals. Animals were treated intragastrically with (-)-linalool dissolved in a $1 \%$ Tween 20 at the doses of 40, 120 and $360 \mathrm{mg} / \mathrm{kg} / \mathrm{day}$. The control group was administered with appropriate volume of vehicle $(5 \%$ glucose $+1 \%$ Tween $20,1 \mathrm{ml} / \mathrm{kg}$ ). The administration was carried out for 13 consecutive days. Animals were sacrificed by decapitation $24 \mathrm{~h}$ after the last drug administration and the liver was sampled and frozen until microsomes isolation.

\section{Chemicals}

(-)-Linalool, NADP, glucose-6-phosphate, glucose-6-phosphate-dehydrogenase, $\quad \mathrm{MgCl}_{2} \cdot 6 \mathrm{H}_{2} \mathrm{O}$, EDTA, $\mathrm{KH}_{2} \mathrm{PO}_{4}, \mathrm{Na}_{2} \mathrm{HPO}_{4}, \mathrm{HCl}$, prednisone, ibuprofen, testosterone, diclofenac, Tween 20, KCl, Tris, 4'-hydroxydiclofenac and sucrose were provided by Sigma-Aldrich (St. Louis, MO, USA). Metabolites of

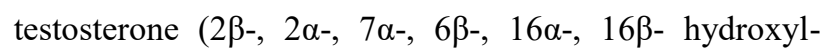
testosterone) were purchased from Steraloids Inc. (Newport, RI, USA). All the organic solvents were of HPLC purity (acetonitrile, methanol, dichloromethane and diethyl ether) and were supplied by Lach-Ner (Neratovice, CZ).

\section{Preparation of RLM}

Microsomes were isolated from 3 grams of liver tissue of individual animals by differential ultracentrifugation $(19000 \mathrm{~g}$ for $20 \mathrm{~min}$ and $2 \times 105000 \mathrm{~g}$ ) in $20 \mathrm{mM}$ Tris $/ \mathrm{KCl}$ and finally diluted in $0.25 \mathrm{M}$ Tris/sucrose buffer $(\mathrm{pH}=7.4)$. The total protein content in the microsomal preparations was assessed according to Lowry et al. (1951) method using the bovine serum albumin as a standard. Total CYP content was assessed by CO-difference spectroscopy according to Omura et al. (1964) method.

\section{Determination of Cytochrome P450 activity in RLM}

The activities of CYP2A, 2B, 2C11 and 3A were assessed by measuring the rate of testosterone hydroxylation in positions: $7 \alpha$ (CYP2A), $16 \beta$ (CYP2B), $2 \alpha$ and $16 \alpha$ (CYP2C11), $2 \beta$ and $6 \beta$ (CYP3A) according to the modified method of Wójcikowsky et al. (2008) with slight modifications (Turjap et al. 2014) as was described previously (Dovrtělová et al. 2015). The activity of CYP2C6 was assessed by measuring the rate of 4 '-hydroxylation of diclofenac. Incubation mixture of final volume $0.5 \mathrm{ml}$ containing phosphate buffer $(50 \mathrm{mM}$, $\mathrm{pH}=7.4)$, EDTA (1.1 mM), NADP (1.2 mM), glucose-6phosphate (4.4 mM), $\mathrm{MgCl}_{2} .6 \mathrm{H}_{2} \mathrm{O}(3.2 \mathrm{mM})$, glucose6-phosphate-dehydrogenase $(0.5 \mathrm{U}$ in $0.5 \mathrm{ml}), 50 \mu \mathrm{l}$ of RLM (1 mg/ml of protein) and diclofenac $(100 \mu \mathrm{M})$. Drugs' effects were evaluated in the range of linear dependence of the product formation on time and concentrations of substrates. The reaction was carried out at $37^{\circ} \mathrm{C}$ on horizontal vortex at $180 \mathrm{rpm}$ and stopped after $20 \mathrm{~min}$ by addition of $50 \mu \mathrm{l}$ of ice cold methanol and cooling down on the ice. Metabolites formed during activity assays were measured by HPLC (Shimadzu LC-10) with the DAD detector (Shimadzu SPD-M10AVP). Internal standard (ibuprofen) was added to the analytes and 4'-hydroxydiclofenac was extracted by $10 \mathrm{~min}$ of vortexing with diethyl ether $(4 \mathrm{ml})$. The residue obtained after evaporation of extracts was dissolved in $250 \mu \mathrm{l}$ of mobile phase. An aliquot of $20 \mu \mathrm{l}$ was injected into the HPLC system and the mobile phase was used in following isocratic mode: $57: 43 \mathrm{v} / \mathrm{v} \mathrm{KH}_{2} \mathrm{PO}_{4}$ ( $20 \mathrm{mM}$, adjusted to $\mathrm{pH}=2.8$ )/acetonitrile. The flow rate was $0.55 \mathrm{ml} / \mathrm{min}$. Analytical column (Kinetex C18 2.6u, $150 \times 4.6 \mathrm{~mm}$ ) was purchased from Phenomenex (Torrance, CA, USA). The absorbance was measured with DAD detector at the wavelength $225 \mathrm{~nm}$ (ibuprofen) and $276 \mathrm{~nm}$ (diclofenac and 4'-hydroxydiclofenac). Metabolic activities of all CYP enzymes were expressed as the metabolite molar concentration $/ \mathrm{min} / \mathrm{mg}$ of total protein in RLM. Inhibitory potency of (-)-linalool on CYP2C6 metabolic activity was evaluated in RLM incubated with diclofenac after 10 min of pre-incubation with (-)-linalool (1 $\mu \mathrm{M}-1 \mathrm{mM})$. 


\section{Data analysis}

Data were statistically evaluated with the Statistica 12 software (StaSoft, Inc. 2013) using nonparametric Kruskal-Wallis test. Results were regarded as statistically significant when $\mathrm{p} \leq 0.05 . \quad \mathrm{IC}_{50}$ value was determined through nonlinear regression of relative reaction rate at single substrate concentration $(25 \mu \mathrm{M})$ and $0.25 \mathrm{mg} / \mathrm{ml}$ of total protein in the presence of varying inhibitor concentrations ( $1 \mathrm{nM}-1 \mathrm{mM})$ and calculated by using SigmaPlot (SPSS, Inc., Chicago).

\section{Results}

Neither total protein content nor total CYP content in RLM were affected by any of treatments (Fig. 1). Treatment with (-)-linalool showed insignificant, dose dependent tendency with increase in the rate of testosterone $\quad 7 \alpha-(\mathrm{CYP} 2 \mathrm{~A}), \quad 6 \beta-(\mathrm{CYP} 3 \mathrm{~A}), \quad$ and $16 \beta$-hydroxylation (CYP2C11) but only dose $360 \mathrm{mg} / \mathrm{kg}$ exhibited statistically significant increase in the rate of $7 \alpha$-hydroxylation of testosterone (CYP2A) (Fig. 2). (-)-Linalool exhibited also dose-dependent trend on the rate of 4'-hydroxylation of diclofenac (CYP2C6) which did not reach statistical significance at any of treatment regimes (Fig. 2). Within $1 \mathrm{nM}-1 \mathrm{mM}$ (-)-linalool exhibited weak competitive inhibition of CYP2C6, with $\mathrm{IC}_{50}$ of $84 \mu \mathrm{M}$ (Fig. 3).
A

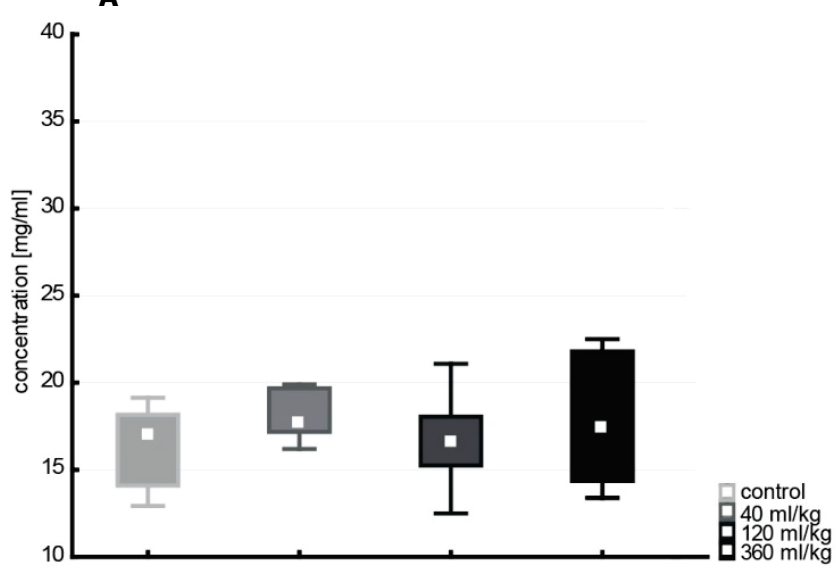

B

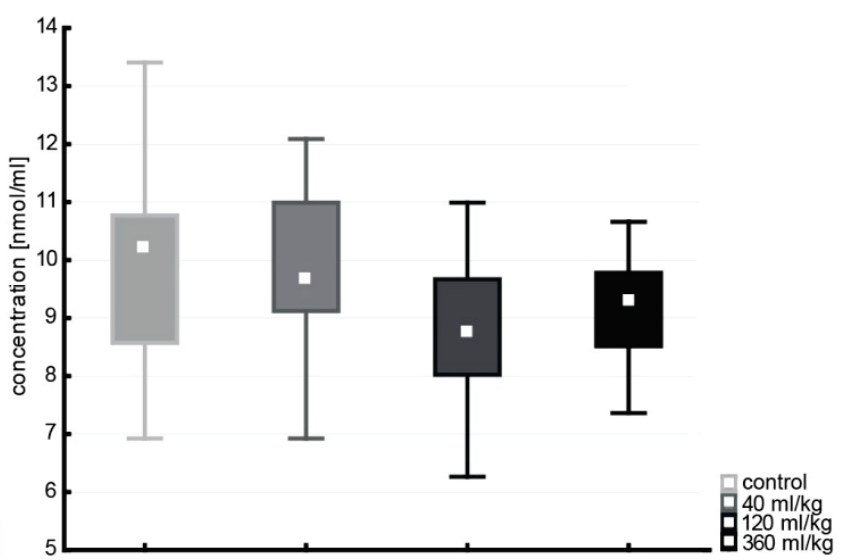

Fig. 1. The effect of subchronic administration of (-)-linalool on total protein (A) and total CYP content (B) in RLM. Values expressed as box plots with median (box $25-75 \%$, whiskers min - max outliers).

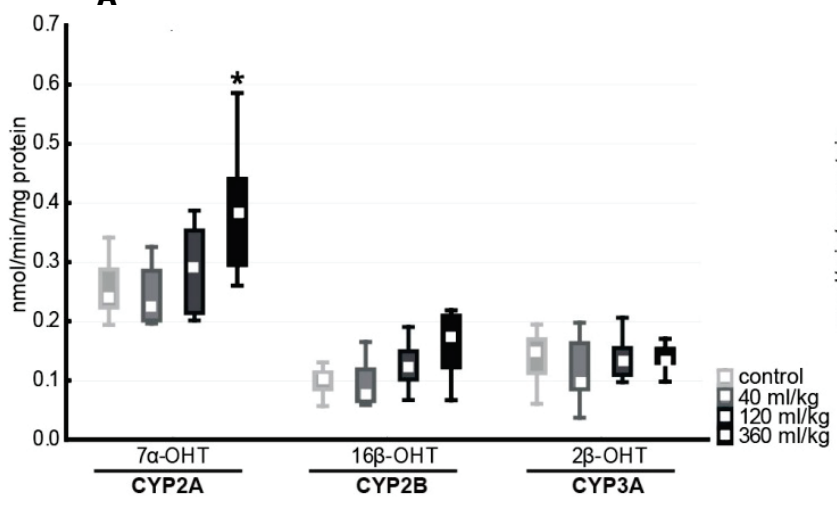

B

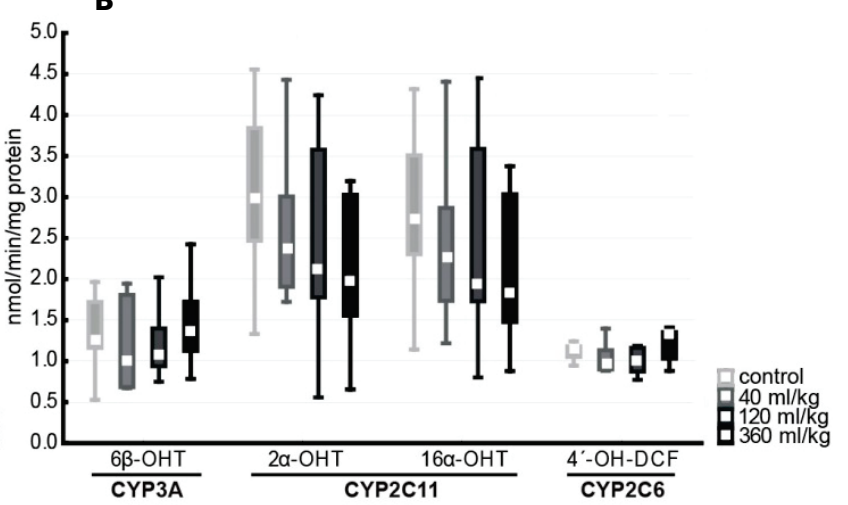

Fig. 2. The metabolic activity of selected CYP enzymes in RLM after systemic subchronic administration of (-)-linalool expressed as $\mathrm{nmol} / \mathrm{min} / \mathrm{mg}$ of total protein ( $\mathrm{OHT}=$ hydroxytestosterone, $4^{\prime}-\mathrm{OH}-\mathrm{DCF}=4^{\prime}$-hydroxydiclofenac). All values are expressed as box plots with median (box $25-75 \%$, whiskers min-max without outliers). Statistical significance with respect to the control group is indicated with ${ }^{*} p \leq 0.05$. 


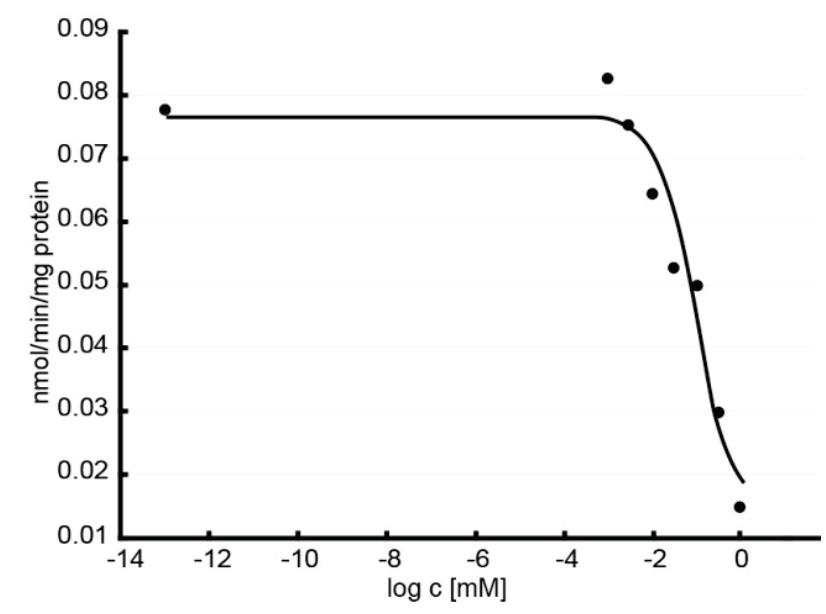

Fig. 3. Effect of (-)-linalool on the in vitro biotransformation of diclofenac to 4 '-hydroxydiclofenac by RLM with NADPH generating system. A fixed concentration of diclofenac $(25 \mu \mathrm{M})$ was incubated with various concentrations of (-)-linalool $(1 \mathrm{nM}-1 \mathrm{mM})$. The $\mathrm{IC}_{50}$ value was determined by nonlinear regression analysis.

\section{Discussion}

The objective of this study was to assess in vitro metabolic activity of selected CYP enzymes in RLM after subchronic administration of (-)-linalool to rats. The metabolic activity of CYP2A, CYP2B, CYP2C11 and CYP3A was assessed with the use of testosterone and the metabolic activity of CYP2C6 with diclofenac as a probe substrate. The results from the study demonstrate that dose $360 \mathrm{mg} / \mathrm{kg}$ of (-)-linalool significantly increased the rate of $7 \alpha$-hydroxylation of testosterone, which correspond to increased metabolic activity of CYP2A. In rat, the CYP2A family includes CYP2A1, CYP2A2 occurring in hepatic tissue and CYP2A3 occurring in lungs. The rat CYP2A show about $60 \%$ homology in amino acid sequence to human CYP2A6 (Martignoni et al. 2006). There are only few drugs which are predominantly metabolized via CYP2A (coumarin, nicotine), whereas for the most of xenobiotic substrates CYP2A represents only minor pathway of their biotransformation (halothane, methoxyflurane, valproic acid etc.). However, CYP2A displays restricted substrate specificity, it was found that can metabolically activate a number of carcinogens including nitrosamines and aflatoxins (Raunio et al. 2008).

To the best of our knowledge, up to date there is no study which tested the effect of (-)-linalool on CYP enzymes. Doroshyenko et al. (2013) evaluated effect of lavender oil preparation in 16 humans with result that $160 \mathrm{mg} /$ day of lavender oil preparation had no clinically relevant effect on CYP1A2, CYP2C9, CYP2C19, CYP2D6 and CYP3A4 enzymes in vivo. Kasper et al. (2013) reviewed 7 clinical trials investigating the anxiolytic efficacy of lavender oil preparation, which generally confirmed that doses $80-160 \mathrm{mg} /$ day have the anxiolytic effect in patients with subsyndromal anxiety and generalised anxiety disorder. The doses tested by ours in the experiment with subchronic administration of (-)-linalool to rats were much higher, and therefore we assume that possible influence of linalool on drug metabolizing enzymes is not clinically relevant.

\section{Conclusions}

In the light of our results, (-)-linalool could be considered as safe anxiolytic/antidepressant adjuvant to conventional treatment in the light of drug-drug interactions. For confirmation of our results, it is necessary to replicate our results in other experimental system, e.g. human liver microsomes or immobilized CYP microreactor system (Schejbal et al. 2016) which could enable repeated use of human CYP enzymes with series of CYP probe substrates.

\section{Conflict of Interest}

There is no conflict of interest.

\section{Acknowledgements}

This work was supported by the grant of Grant agency of Czech Republic No. GA16-06106S and written at Masaryk university as a part of the project „Experimental pharmacological development in neuropsychopharmacology and oncology" number MUNI/A/1284/2015 with the support of the Specific University Research Grant, as provided by the Ministry of Education, Youth and Sports of the Czech Republic in the year 2016.

\section{References}

APROTOSOAIE AC, HĂNCIANU M, COSTACHE II, MIRON A: Linalool: a review on a key odorant molecule with valuable biological properties. Flavour Fragr J 29: 193-219, 2014.

Committee on Herbal Medicinal Products (HMPC): Assessment report on Lavandula angustifolia Miller, aetheroleum and Lavandula angustifolia Miller, flos. European Union herbal monograph. 2012. 
DOROSHYENKO O, ROKITTA D, ZADOYAN G, KLEMENT S, SCHLÄFKE S, DIENEL A, GRAMATTÉ T, LÜCK H, FUHR U: Drug cocktail interaction study on the effect of the orally administered lavender oil preparation silexan on cytochrome P450 enzymes in healthy volunteers. Drug Metab Dispos 41: 987-993, 2013.

DOVRTĚLOVÁ G, NOSKOVÁ K, JUŘICA J, TURJAP M, ZENDULKA O: Can bioactive compounds of Crocus sativus L. influence the metabolic activity of selected CYP enzymes in the rat? Physiol Res 64 (Suppl. 4): S453-S458, 2015.

ELISABETSKY E, BRUM LF, SOUZA DO: Anticonvulsant properties of linalool in glutamate-related seizure models. Phytomedicine 6: 107-113, 1999.

KASPER S, GASTPAR M, MÜLLER WE, VOLZ HP, MÖLLER HJ, DIENEL A, SCHLÄFKE S: Efficacy and safety of Silexan, a new, orally administered lavender oil preparation, in subthreshold anxiety disorder - evidence from clinical trials. Wien Med Wochenschr 160: 547-556, 2010.

KASPER S: An orally administered lavandula oil preparation (Silexan) for anxiety disorder and related conditions: an evidence based review. Int J Psychiatry Clin Pract 17 (Suppl. 1): 15-22, 2013.

LIU K, CHEN Q, LIU Y, ZHOU X, WANG X: Isolation and biological activities of decanal, linalool, valencene, and octanal from sweet orange oil. J Food Sci 77: C1156-C1161, 2012.

LI XJ, YANG YJ, LI YS, ZHANG WK, TANG HB: $\alpha$-Pinene, linalool, and 1-octanol contribute to the topical antiinflammatory and analgesic activities of frankincense by inhibiting COX-2. J Ethnopharmacol 179: 22-26, 2016.

LOWRY OH, ROSEBROUGH NJ, FARR AL, RANDALL RJ: Protein Measurement with the Folin Phenol Reagent. J Biol Chem 193: 265-275, 1951.

MARTIGNONI M, GROOTHUIS GMM, DE KANTER R: Species differences between mouse, rat, dog, monkey and human CYP-mediated drug metabolism, inhibition and induction. Expert Opin Drug Metab Toxicol 2: 875-894, 2006.

OMURA T, SATO R: The carbon monooxide-binding pigment of liver microsomes. I. Evidence for its hemoprotein in nature. J Biol Chem 239: 2370-2378, 1964.

PARK SN, LIM YK, FREIRE MO, CHO E, JIN D, KOOK JK: Antimicrobial effect of linalool and $\alpha$-terpineol against periodontopathic and cariogenic bacteria. Anaerobe 18: 369-372, 2012.

PEANA AT, D'AQUILA PS, PANIN F, SERRA G, PIPPIA P, MORETTI MDL: Anti-inflammatory activity of linalool and linalyl acetate constituents of essential oils. Phytomedicine 9: 721-726, 2002.

RAUNIO H, HAKKOLA J, PELKONEN O: The CYP2A Subfamily. In: Cytochromes P450: Role in the Metabolism and Toxicity of Drugs and Other Xenobiotics. IOANNIDES C (ed.), Royal Society of Chemistry, Cambridge, 2008, pp 150-177.

SCHEJBAL J, ŘEMÍNEK R, ZEMAN L, MÁDR A, GLATZ Z: On-line coupling of immobilized cytochrome P450 microreactor and capillary electrophoresis: A promising tool for drug development. $J$ Chromatogr A 1437: 234-240, 2016.

SOUTO-MAIOR FN, De CARVALHO FL, De MORAis LC, NeTto SM, De SOUSA DP, De ALMEIDA RN: Anxiolytic-like effects of inhaled linalool oxide in experimental mouse anxiety models. Pharmacol Biochem Behav 100: 259-263, 2011.

SUGAWARA Y, HARA C, TAMURA K, FUJII T, NAKAMURA K, MASUJIMA T, AOKI T: Sedative effect on humans of inhalation of essential oil of linalool: Sensory evaluation and physiological measurements using optically active linalools. Anal Chim Acta 365: 293-299, 1998.

TURJAP M, DOVRTĚLOVÁ G, NOSKOVÁ K, ZENDULKA O, JUŘICA J: Determination of testosterone and its 5 metabolites in the incubation media as a measure of cytochrome P450 metabolic activity. In: 11th International Interdisciplinary Meeting on Bioanalysis. FORET F, KŘENKOVÁ J, DROBNÍKOVÁ I, GUTTMAN A, KLEPÁRNÍK K (eds), Institute of Analytical Chemistry of the CAS, Brno, 2014, pp 270-273.

UEHLEKE B, SCHAPER S, DIENEL A, SCHLAEFKE S, STANGE R: Phase II trial on the effects of Silexan in patients with neurasthenia, post-traumatic stress disorder or somatization disorder. Phytomedicine 19: 665-671, 2012. 
WÓJCIKOWSKI J, GOŁEMBIOWSKA K, DANIEL WA: Regulation of liver cytochrome P450 by activation of brain dopaminergic system: Physiological and pharmacological implications. Biochem Pharmacol 76: 258-267, 2008.

ZALACHORAS I, KAGIAVA A, VOKOU D, THEOPHILIDIS G: Assessing the local anesthetic effect of five essential oil constituents. Planta Med 76: 1647-1653, 2010. 